\title{
RESENHA DA NOVA EDIÇÃO DIGITAL, REVISADA E MODERNIZADA DO LIVRO EDUCAÇÃO MUSICAL ATRAVÉS DO TECLADO VOLUME 1 - MUSICALIZAÇÃO, DE MARIA DE LOURDES JUNQUEIRA GONÇALVES E CACILDA BORGES BARBOSA. REVISORES: TIAGO BATISTONE E INGRID BARANCOSKI.
}

REVIEU OF THE NEU, REVISED AND MODERNIZED DIGITAL EDITION OF THE BOOK MUSICAL EDUCATION THROUGH THE KEYBOARD VOLUME 1 - MUSICALIZATION, BY MARIA DE LOURDES JUNQUEIRA GONÇALVES AND CACILDA BORGES BARBOSA. EDITORS: TIAGO BATISTONE AND INGRID BARANCOSKI.

\author{
Fátima Corvisier \\ Universidade de São Paulo \\ fatimacorvisier@usp.br
}

\section{Resenha}

BARANCOSKI, Ingrid e BATISTONE, Tiago, org. Educação musical através do teclado - $1 \%$ Volume Musicalização. BARBOSA, Cacilda Borges e CONCCALVES, Maria de Lourdes Junqueira. $9^{\circ}$. edição digital, modernizada e revisada. Rio de Janeiro: UNIRIO, 2019.

BARANCOSKI, Ingrid e BATISTONE, Tiago, org. Educação musical través do teclado - $1^{\text {o }}$ Volume Musicalização - Manual do professor. CONÇALVES, Maria de Lourdes Junqueira. 3a. edição digital, modernizada e revisada. Rio de Janeiro: UNIRIO, 2019.

Desde o lançamento do primeiro volume, em 1985, a série de livros didáticos Educação musical através do teclado (doravante EMaT) da pianista e pedagoga Maria de Lourdes Junqueira Gonçalves (192420 15) e da compositora Cacilda Borges Barbosa ( 19 | 4-20 I0) desperta a atenção de professores dedicados ao ensino do piano e motiva 
alunos iniciantes no instrumento. Esta coleção, agora apresentada em nova edição modernizada e revisada, em formato digital, realizada por Tiago Batistone e pela Profa. Dra. Ingrid Barancoski (UNIRIO)!, vem preencher uma lacuna há muito sentida no âmbito da pedagogia do piano no Brasil. Por motivos diversos, que os revisores enumeram em sua introdução à série, os livros da EMaT não eram mais encontrados facilmente por aqueles desejosos de recorrer a uma metodologia sólida e eficiente para a iniciação musical ao piano; um material didáticopedagógico alicerçado nas pesquisas de grandes pedagogos musicais do século XX, como Louise Bianchi, Robert Pace, Frances Clark e James Lyke.

Após travar conhecimento com a metodologia do Ensino de Piano em Grupo, Gonçalves entrou em contato com renomados professores estadunidenses e após um período de 4 meses em que esteve em 8 instituições americanas de ensino de música, mais notadamente na Southern Methodist University em Dallas, Texas e na Illinois University at Urbana - Champaign, Illinois, trouxe para o Brasil as ideias que se materializaram na publicação da série Educação musical através do teclado. Cativada pela filosofia da iniciação musical através do Piano em Grupo, na qual o aluno é musicalizado através do instrumento em um ambiente motivador, Gonçalves reaviva a concepção de ensino de seu professor de Pedagogia Musical, Antônio de Sá Pereira (18881966), na qual a musicalização deveria ser o passo inicial para o aprendizado musical, diferentemente do ensino tradicional que tentava "pianizar precocemente o aluno" (nas palavras da própria Maria de Lourdes Junqueira Gonçalves)2.

A série é formada por 10 livros, sendo 5 livros do aluno, divididos em Volume 1 - Musicalização, Volume 2 - Leitura nas Teclas Brancas, Volume 3 - Leituras nas Teclas Brancas e Pretas, Volume 4 - Habilidades Funcionais A, Volume 5 - Habilidades Funcionais B e 5 Manuais do Professor, que acompanham cada um desses volumes. A presente edição

I Resultado do plano de estudo "Educação Musical através do Teclado: Revisitando o método de Maria de Lourdes Junqueira Conçalves" realizado por Tiago Batistone, com apoio de bolsa de iniciação científica e que integra o projeto de pesquisa "Ensino do piano", sob coordenação da Profa. Dra. Ingrid Barancoski, docente titular da UNIRIO (Universidade Federal do Estado do Rio de Janeiro).

2 Em conversa informal com a autora desta Resenha, em sua residência no Rio de Janeiro, em 2010. 
digital revisou e modernizou o Volume I - Musicalização e o Manual do Professor correspondente.

A obra é pensada como um curso de musicalização tendo o piano como instrumento musicalizador. $\bigcirc$ objetivo principal é desenvolver a musicalidade e alfabetizar musicalmente e não apenas pensar na formação do pianista, e sim do músico completo ("ensino integrado música/instrumento"). ${ }^{3} \bigcirc$ primeiro volume parte da experimentação do teclado para "a página musical", pela leitura, buscando a intimidade do aluno com o som, o ritmo, a harmonia e a transposição. Criação (composição) e percepção musical enriquecem as atividades propostas e permitem que o aluno vivencie o universo musical em uma atmosfera lúdica. Ainda na apresentação da série, Conçalves (2011) enfatiza que seu propósito é tecer a correlação entre executar, criar e ouvir música, "sem objetivos preconcebidos de orientação para a profissão ou para - lazer e sim por seu valor no enriquecimento da vida das pessoas e da sociedade", pois que a educação musical deve ser dada a todos os indivíduos, sem a preocupação da detecção precoce do talento musical. Como explica a autora, apesar de haver sido pensada para o ensino de piano em grupo, a EMaT também pode ser aplicada no ensino individual, porém, tendo o professor como participante das atividades que caberiam aos outros integrantes do grupo.

\section{A Introdução do Manual do Professor - Musicalização} apresenta fatos relevantes que contextualizam a obra em vista das ideias e atividades desenvolvidas pelas autoras, além de revelar as circunstâncias que estimularam a elaboração da presente edição digital. $\bigcirc$ Prefácio relata decisões editoriais importantes, bem aplicadas, que tornaram a publicação bem mais atraente. Os diversos comentários e notas de rodapé, como em relação à atualização de equipamentos para o ensino de piano em grupo, são muito pertinentes e necessários para o bom aproveitamento dessa metodologia. $\bigcirc$ desenho gráfico modernizou a EMaT e trouxe uma enorme clareza à leitura do conteúdo, pois distribuiu figuras e texto de forma mais proporcional e organizada, dando à obra uma aparência profissional, que faltava às edições anteriores. Quanto ao conteúdo, o Manual do Professor mantém o texto original, com algumas correções de ortografia e nova diagramação, congruentes com sua modernização. Suas seções são assim distribuidas:

3 Gonçalves, Maria de Lourdes J.; Barbosa, Cacilda B. Manual do Professor - Musicalização (20/ l), p.vi.

4 Idem, p.v. 
Introdução; Prefácio; Apresentação; I. Ensino individual ou em grupo?; 2. Ensino de piano em grupo; 3. $\bigcirc$ Processo de leitura adotado na série EMaT; 4. Breve análise do $1^{10}$ volume; Anexo I (Harmonizações); Anexo II (Posições de mão); Anexo III (Biografia da autora: Quem é Maria de Lourdes?). A apresentação da obra é a mesma publicada pela autora em julho de 1985, aqui reproduzida como se encontra nas antigas edições. $\bigcirc$ primeiro capítulo traz um breve histórico do Ensino de Piano em Grupo e fala da importância dessa metodologia para o ensino musical sem deixar de apontar as controvérsias que o ensino de piano em grupo pode suscitar. No capítulo seguinte, analisa de forma bem criteriosa os fatores que caracterizam essa metodologia, a saber: 1. o planejamento do grupo (o grau de musicalização, a faixa etária ideal dos alunos, o limite de vagas em cada turma, a cronometragem e frequência das aulas) e o planejamento didático (o conteúdo para o planejamento do curso, a sequência para a distribuição da matéria em unidades didáticas, a distribuição das atividades para o planejamento da aula); 2. o equipamento necessário para se ter em sala de aula; 3. Procedimentos básicos de ensino que incluem as atitudes do professor em sala de aula, a manutenção da disciplina e procedimentos metodológicos; 4. características metodológicas, que resumem as características anteriormente citadas. $\bigcirc$ terceiro capítulo é dedicado ao processo de leitura adotado na série. Para a leitura das alturas, a autora adota o sistema de leitura intervalar surgido na década de 1950 nos Estados Unidos, que "enfatiza o desenvolvimento da leitura espacial-direcional conectada com a fôrma da mão e a movimentação gerada pelo reconhecimento intervalar" (USZLER, 2000). Para a leitura rítmica a autora inicia a série com clusters e valores indeterminados, fazendo referência a valores curtos e longos, somente. Mais tarde, ainda no primeiro volume, o aluno aprende as figuras da semínima, mínima e mínima pontuada, sem alusão a fórmulas de compasso. Como relata Conçalves (2019), o processo é lento, mas eficiente. A contagem é feita de maneira silábica em todos os volumes da série e, para tal, há uma explicação detalhada de como esse tipo de contagem deve ser praticado. No quarto e último capítulo, é feita uma breve análise do primeiro volume da série. Esta análise se divide em duas partes: os cinco primeiros capítulos da primeira seção do livro - Experiências e descobertas, e a análise dos cinco capítulos restantes, pertencentes à segunda seção - Pré-leitura. Cada um desses capítulos é minuciosamente explicado, mas ao invés de uma orientação pormenorizada quanto aos planos de aula, a autora deixa liberdade para que o professor use sua própria criatividade no planejamento das atividades. Vale ressaltar 
que na página 60, primeira linha, há um erro de digitação proveniente da cópia do texto da antiga edição, em que deve-se ler $8^{\circ}$ capítulo ao invés de terceiro. $\bigcirc$ mesmo acontece na página 61 , início do quarto parágrafo, onde deve-se ler $9^{10}$ capítulo no lugar de quarto. Seguindo o Anexo I, contendo as harmonizações para que o professor acompanhe o aluno em suas peças de repertório, é apresentado o Anexo II. Este, constituido por fotos das posições das mãos, deixou de mostrar duas das quatro fotos - a posição em arco e a posição aberta - apresentadas na antiga edição. A falta dessas duas fotografias pode dificultar a compreensão dessas posições. Fica a sugestão da elaboração de um vídeo explicativo, cujo link ou QR Code, impresso na publicação, poderia esclarecer aos leitores como essas posições de mão podem ser alcançadas. De extrema importância foi a inclusão da biografia de Maria de Lourdes Junqueira Conçalves no Anexo III, uma vez que as gerações mais jovens não conhecem quem foi esta brilhante pianista e pedagoga, cujo excelente trabalho, único dessa qualidade em língua portuguesa, é agora revivido nesta primorosa edição digital.

O livro do aluno - Musicalização traz em seu prefácio algumas explicações para decisões editoriais tomadas pelos organizadores, fala da gênese do trabalho de pesquisa, que resultou na moderna edição digital, e aponta para a continuação do trabalho, com a futura elaboração da edição digital dos 8 volumes restantes. A apresentação visual é convidativa e a organização de textos, caixas de textos, quadros e figuras confere a esta edição digital um padrão profissional, esteticamente agradável, que faltava às antigas edições. A nova diagramação proporcionou melhor compreensão do conteúdo do livro e sua sequência, uma vez que está mais espaçado e em cores, com fontes tipográficas diferenciadas, que seguem uma lógica por toda a obra. Foi muito positiva, além de bem justificada, a inclusão das páginas onde o aluno anotará suas composições. A utilização de caixas de texto para explicação de novos conceitos e a inserção de mais instruções sobre atividades ou figuras apresentadas destacou elementos de maior importância no livro e tornou mais fácil acompanhar a leitura. De forma geral, o layout da obra foi modernizado e a aproximou das publicações semelhantes, atuais. A elaboração do Sumário, ausente nas edições antigas, também foi providencial. Dividido em duas partes, apresenta inicialmente "Experiências e descobertas" para depois prosseguir na parte intitulada "Pré-leitura". Cada uma dessas duas partes divide-se em cinco capítulos. Na edição anterior cada parte listava os capítulos de I a 5. Nesta moderna edição digital, os capítulos se sucedem de l a 
10. Assim são indicados: 1. O retrato do cluster; 2. Sons curtos e longos; 3. $\bigcirc$ som que anda sozinho; 4. A nota redonda; 5 . $\bigcirc$ arco; 6 . Linhas $e$ espaços; 7. O salto; 8. O passo; 9. O nome das teclas; 10. Os Dós e as regiões do teclado.

livro inicia com atividades que exploram sons graves e agudos, curtos e longos, fortes e suaves nas posições em cluster em grupos de notas pretas e brancas e na posição de mão fechada, quando só o segundo dedo toca notas isoladas, tendo sua articulação interfalangiana distal apoiada pelo polegar. Fotos coloridas demonstram como devem ser essas duas posições de mão. Assim que é apresentada a notação do cluster, iniciam-se as atividades de reconhecimento de leitura e sua correspondência com a movimentação ascendente, descendente e de repetição de sons e sua relação com o teclado. Exercícios de percepção musical e de composição são logo apresentados e estão presentes em todos os capítulos. $\bigcirc$ capítulo 2 trabalha sons curtos e longos (notação do cluster preto ou branco) e embora a contagem ainda não seja requerida, o aluno é induzido a sentir o som curto como metade do longo. Atividades para o ganho de coordenação motora investem em uso de mãos alternadas e juntas. Os diversos padrões de movimentação são combinados com variações de dinâmica (forte e piano) e as distintas regiões do teclado (agudo, médio e grave, subir e descer, esquerda e direita). $\bigcirc$ exercício de composição remete o aluno ao uso dos cartões musicais que ele recortará no decorrer das lições e que serão usados nas atividades de criação. As peças de repertório trazem o diagrama do teclado indicando quais os clusters ou notas serão utilizados e as letras dessas pequenas canções sempre refletem o caráter expresso pela música. $\bigcirc$ capítulo termina com a apresentação do dedilhado, de forma lúdica. $\bigcirc$ terceiro capítulo reforça a relação entre duração longa e curta, e movimentos ascendente, descendente, repetido, ou vai-e-vem, com a leitura. No capítulo 4 são apresentadas as notas "redondas" - as semínimas e mínimas, diferenciadas da notação anterior, do cluster (quadrado), para representar os sons curtos e longos. A contagem silábica tem início com essas duas figuras, assim como as primeiras transposições. $\bigcirc$ quinto capítulo apresenta o "arco" (quintas harmônicas) e trabalha a posição de mão do aluno e a formação da arcada. Neste capítulo iniciam-se os "exercícios diários" que juntamente com os "deveres de casa" (já antes requeridos) ensinam o aluno a manter uma disciplina de estudo. Aparece o primeiro exercício para técnica de 5 dedos, com mãos separadas e surge a primeira atividade 
para piano a quatro mãos. A primeira parte do livro se encerra com um recital de piano.

A segunda parte se inicia no capítulo 6 apresentando as notas nas linhas e espaços, no sistema de leitura intervalar, mencionado acima. Muitas atividades reforçam o que foi aprendido até então. Os capítulos 7 e 8 trabalham os conceitos de salto (intervalo de 3a.) e o passo (intervalo de $2^{a}$.), respectivamente. $\bigcirc$ número de linhas na pauta chega até ao pentagrama, porém sua utilização ainda é intercalada com o uso de peças com menos linhas, característica do sistema intervalar de leitura musical. Ainda não são usadas as claves, nem barras ou fórmulas de compasso. A mínima pontuada é apresentada. No capítulo 9 os nomes das teclas brancas são apresentados e com isso o passo e o salto passam a ser chamados de intervalos de segunda e terça. $\bigcirc$ dedilhado nas peças é minimamente indicado e a leitura é relacionada à topografia do teclado e à movimentação na pauta, não aos números dos dedos. $\bigcirc$ conceito de melodia é apresentado e surgem os repertórios de conjunto. Na seção "Vamos testar?" dois interessantes ditados de intervalos para serem tocados no piano de olhos fechados são experimentados pelo aluno. A seguir, no tópico "composição", o aluno tem à sua frente a peça Colcha de Retalhos que será composta a partir da combinação de diferentes padrões rítmico-melódicos apresentados, trabalhando a aleatoriedade composicional. No término deste capítulo há um segundo recital de piano. O livro termina de fato no capítulo 10, onde são apresentadas as claves de Fá e Sol e as notas Dó l e Dó 5, indicando as regiões grave, média e aguda do teclado. A seguir uma série de atividades práticas e teóricas reforçam o aprendizado das notas com linhas suplementares inferiores e superiores, circundantes a estas duas notas Dó. Após alguns exercícios de recapitulação, o livro finaliza com um certificado de conclusão.

As atividades realizadas são bastante variadas e incluem a exploração do teclado em toda sua extensão, cuidados com a boa formação da posição de mão, atividades lúdicas de ouvir e imitar, ouvir e descobrir, uso de cartões para serem recortados e servirem de material para exercícios de percepção musical e composição, há atividades de criação em todos os capítulos, pré-leitura e posterior leitura intervalar que atinge do Dó I ao Dó 5, transposição, além de conselhos de como estudar e de como realizar os deveres de casa. Enfim, um método completo, pensado para ensinar de maneira divertida. Apontamos uma sugestão: porque não se aproveitar do ambiente digital para incluir,

\section{0}

REV. TULHA, RIBEIRÃO PRETO, v. 6, n. I, pp. 194-205, jan.-jun. 2020 
através de links ou QR-codes, gravuras, fotos, pequenos vídeos, imagens sonorizadas, que remetam o aluno aos títulos das peças presentes no livro? Poderiam ser um estímulo à imaginação sonora da criança.

Os dois livros estão disponíveis gratuitamente para download nos endereços abaixo e no site da rede social eletrônica de contatos acadêmicos "academia.edu": http://www.unirio.br/cla/ivl/publicacoes/ Vol IManualdoProfessorR09.pdf http://www.unirio.br/cla/ivl/publicacoes/ EMAT I livrodoalunoFINAL.pdf (Acesso em 3 1/5/2020).

Só poderíamos concluir felicitando os organizadores, Profa. Dra. Ingrid Barancoski e o discente Tiago Batistone por seu empenho, competência e determinação, por terem enfrentado esse desafio de modernizar, revisar e trazer para o século XXI esta obra inigualável, que merece ser bastante difundida no meio musical brasileiro. É um trabalho considerável, de extrema qualidade e muito relevante para os pedagogos musicais brasileiros, há muito tempo almejantes de um trabalho desta magnitude. Esperamos, ansiosamente, pela publicação do restante da série.

\section{Referências}

GONÇALVES, Maria de Lourdes Junqueira. Educação musical através do teclado - Manual do professor. $1^{\circ}$. volume - Musicalização. $3^{a}$. edição. Rio de Janeiro: edição da autora, 1989.

Educação musical através do teclado Manual do professor. $1^{\circ}$. volume - Musicalização. $4^{\circ}$. edição. Rio de Janeiro: edição da autora, 2011.

GONÇALVES, Maria de Lourdes Junqueira e BARBOSA, Cacilda Borges. Educação musical através do teclado. $1^{\circ}$. volume-Musicalização. $8^{a}$. Edição. Rio de Janeiro: edição das autoras, 2007 a.

PAZ, Ermelinda. Pedagogia Musical Brasileira no Século XX: Metodologias e Tendências. $2^{a}$. edição. Brasilia: Editora MusiMed, 2013.

USZLER, Marianne; CORDON, Stewart; SMITH, Scott M. The Well Tempered Keyboard Teacher. $2^{\circ}$. edição. Belmont, CA: Schirmer Books, 2000. 


\section{Sobre a autora}

Fátima Corvisier - Doutora em Música pela Universidade de São Paulo, graduou- se com Medalha de Ouro na Escola de Música da UFRJ. Forma com o pianista Fernando Corvisier o Duo Corvisier, que se apresenta regularmente no país e no exterior. De suas apresentações internacionais destacamos a palestra-recital realizada em 2007 no Primeiro Encontro de Investigação em Performance promovido pela Universidade de Aveiro, Portugal; apresentação em palestras e recitais, nas universidades de Londres e de Viena em 2013, na Universidade Internacional de Andaluzia, Espanha, em 2016 e em Portugal nas Universidades de Aveiro e Évora em 2019. Desde 2004, Fátima Corvisier é docente de piano do Departamento de Música da FFCLRP-USP, atuando nas áreas de performance e pedagogia do piano.

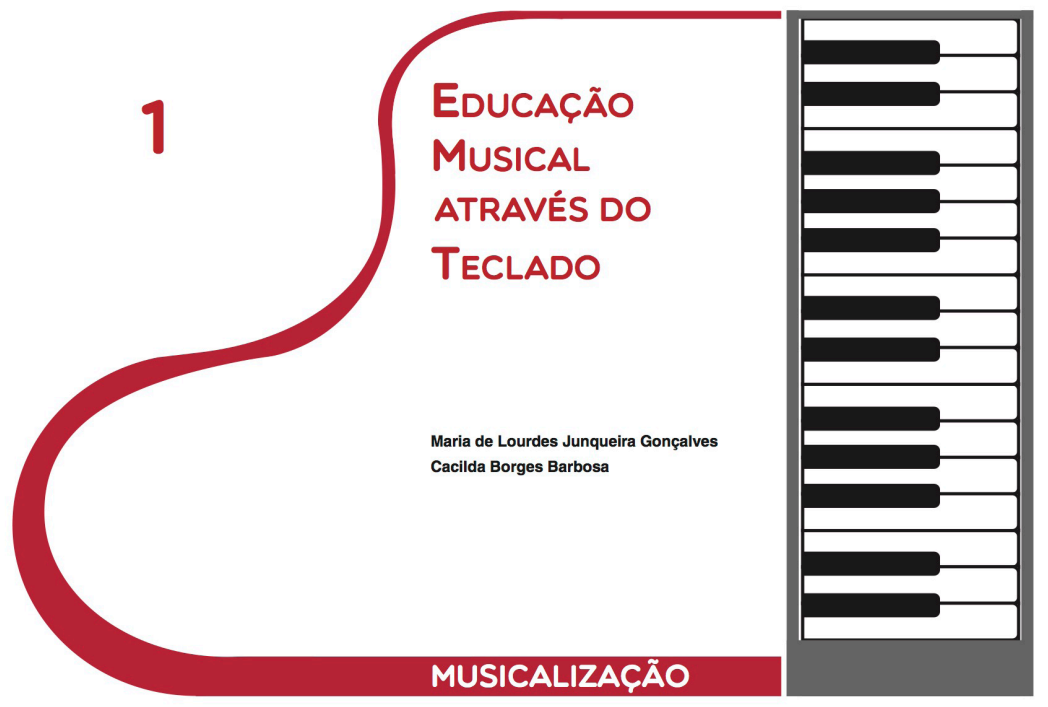


Esta publicação é produto do plano de estudo

"Educação Musical através do Teclado: Revisitando o método de Maria de Lourdes Junqueira Gonçalves" do discente Tiago Batistone, com apoio de bolsa de iniciação científica PIBIC (Vigência 08/2018 a 07/2019) e integra o projeto de pesquisa “Ensino do piano”, sob coordenação da Profa. Ingrid Barancoski, registrado no Portal de pesquisa da UNIRIO.

Modernização e revisão

Tiago Batistone

Ingrid Barancoski

Projeto gráfico e digitalização

Tiago Batistone

Revisão gráfica

Daniel Bruno Nogueira

G635 Gonçalves, Maria de Lourdes Junqueira.

Educação musical através do teclado / Maria de Lourdes Junqueira

Gonçalves, Cacilda Borges Barbosa. - 9. ed. digital, modernizada e revisada por Tiago Batistone e Ingrid Barancoski. - Rio de Janeiro : UNIRIO, 2019.

v. : il.

v.1. Musicalização

ISBN: 978-85-61066-80-2

1. Música - Instrução e estudo. 2. Instrumentos de teclado - Instrução e estudo. I. Barbosa, Cacilda Borges. II. Batistone, Tiago. III. Barancoski,

Ingrid. IV. Universidade Federal do Estado Rio de Janeiro.

CDD -780.7 


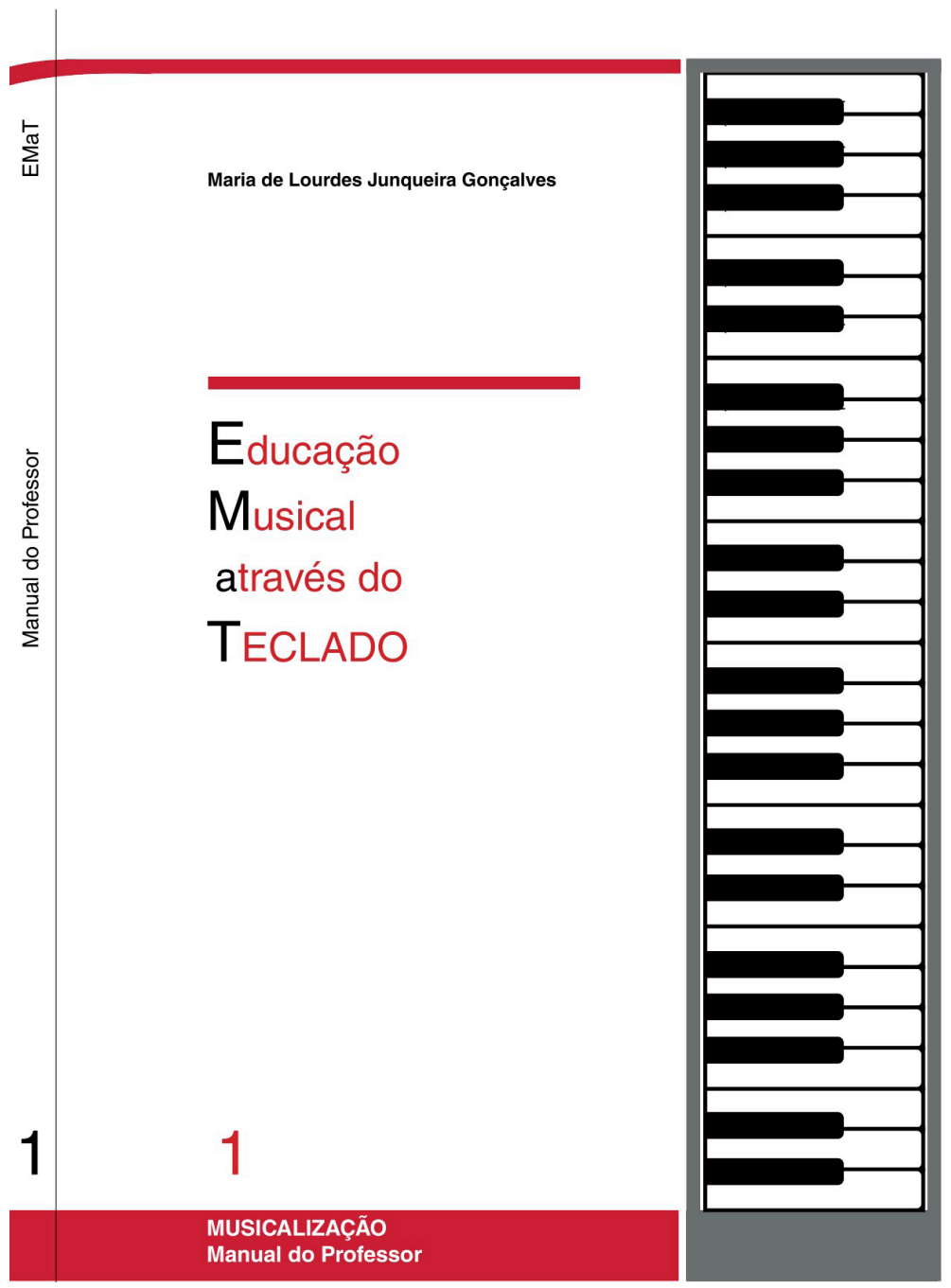


Esta publicação é produto do plano de estudo

"Educação Musical através do Teclado: Revisitando o método de

Maria de Lourdes Junqueira Gonçalves" do discente Tiago Batistone, com apoio de bolsa de iniciação científica PIBIC (vigência 08/2018 a 07/2019) e integra o projeto de pesquisa "Ensino do piano", sob coordenação da Profa. Ingrid Barancoski, registrado no Portal de pesquisa da UNIRIO.

Modernização e revisão

Tiago Batistone

Ingrid Barancoski

Projeto gráfico e digitalização

Tiago Batistone

Gonçalves, Maria de Lourdes Junqueira.

G635 Educação musical através do teclado / Maria de Lourdes Junqueira Gonçalves. - 3. ed. digital, modernizada e revisada por Tiago Batistone e Ingrid Barancoski. - Rio de Janeiro : UNIRIO, 2019.

v. : il.

Conteúdo: v.1. Musicalização - Manual do professor. ISBN: 978-85-61066-81-9.

1. Música - Instrução e estudo. 2. Instrumentos de teclado Instrução e estudo. I. Batistone, Tiago. II. Barancoski, Ingrid. III. Universidade Federal do Estado Rio de Janeiro. 